\title{
Investigation of alternative mechanisms of aquifer-system compaction and land subsidence in Shanghai
}

\author{
Y. Yuan, Y.-S. Xu, S.-L. Shen, and N. Zhang \\ State Key Laboratory of Ocean Engineering, Department of Civil Engineering, \\ Shanghai Jiao Tong University, Shanghai, China \\ Correspondence to: S.-L. Shen (slshen@sjtu.edu.cn)
}

Published: 12 November 2015

\begin{abstract}
Alternative subsidence mechanisms related to groundwater extration and surface loading of built infrastructure in Shanghai have been evaluated to explain continued subsidence despite the controlled reduction of groundwater extraction. The traditional theory of aquifer-system compaction embodied in the aquitard drainage model cannot fully explain this phenomenon. Two possible alternative mechanisms were studied previously: (i) surface loading attributed to urban construction; (ii) creep occuring in sandy deposits of aquifers. These mechanisms could not fully explain the observed subsidence. Two additional alternative mechanistic models are proposed that involve principles of load transfer considering the temporally and spatially redistributed stresses associated with groundwater extraction: (i) the Cosserat continuum mechanism, considering shear force on the permeable coarse-grained matrial in the aquifer due to hydraulic gradients in the aquifer; and (ii) internal erosion of fine-grained (clay and silt) particles within the aquifer. Initial results based on simulations incorporating Cosserat mechanics look promising.
\end{abstract}

\section{Introduction}

The aquifer system in the Yangtze River Delta deposits in Shanghai comprise marine and estuarine sediments with alternating, sub-horizontal strata of permeable, coarse-grained (mostly sand with some silt and clay fraction) strata constituting the aquifers and soft (relatively more compressible), low-permeablity fine-grained (predominately clay and silt) strata constituting the aquitards. The aquitards may be either laterally extensive where they act as confining units in the aquifer system, or interbeded within the aquifers. Generally, when groundwater pumping occurs, groundwater levels decline, causing consolidation of the aquifer system leading to land subsidence. Most of the subsidence in Shanghai has been attributed to the consolidation of the aquitards within the aquifer system.

Recently new subsidence occurring in Shanghai and elsewhere with different geological and hydrogeological conditions, cannot be adequately interpreted using the traditional theory of aquifer-system compaction. Groundwater withdrawal in Shanghai has been controlled, but subsidence has continued since the 1990s. Xu et al. (2009) showed that with the development of urban construction, land subsidence has been poorly correlated with the volume of groundwater withdrawal, but has been well correlated with groundwater drawdown. The groundwater drawdowns have been attributed to the groundwater damming effect of deep foundations for high-rise buildings and other civilian infrastructure. In recent years, field observations show that the percentage of subsidence due to deformation occurring in the aquifers has increased, and that this deformation lags the change in groundwater level. The objective of this paper is to summarize the alternative approaches to illustrate the mechanism of the aforementioned phenomena.

\section{New phenomena of land subsidence}

The thickness of soft deposits of Shanghai is generally $300 \mathrm{~m}$ with a maximum of $400 \mathrm{~m}$. There is one phreatic aquifer group (Aq0) and five confined aquifers (AqI to AqV). The 


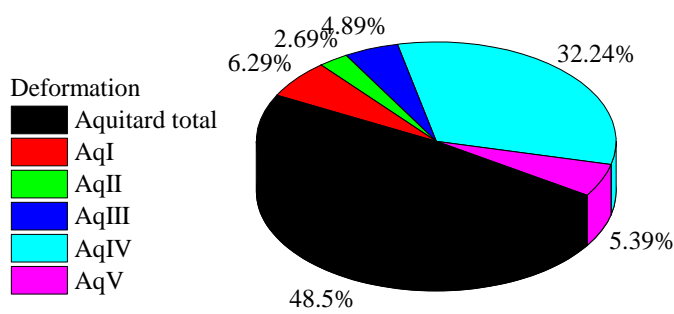

(a) 1980-1995

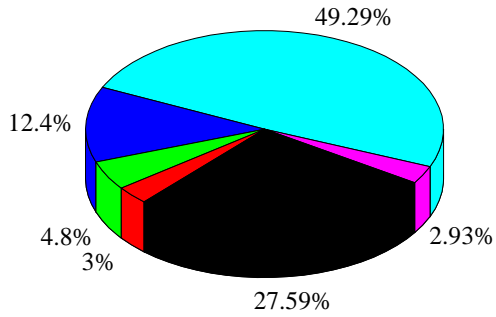

(b) $1996-2000$

Figure 1. Pie chart of deformation of each aquifer in Shanghai (Data from Wei et al., 2010a).

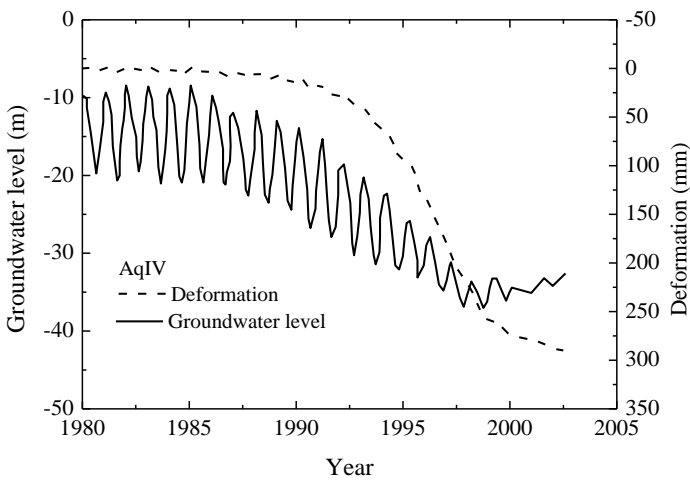

Figure 2. Groundwater level and deformation of AqIV in Yangpu district, Shanghai (Data from Wei et al., 2010b).

aquifers are separated by six aquitards (AdI to AdVI) (Xu et al., 2009). Historical land subsidence in Shanghai, which is mainly due to groundwater withdrawal from AqII to AqV, has been officially recorded since 1921 . Land subsidence was controlled in the 1970s after some measurements were taken. The subsidence rate in the urban center increased again under the same conditions of groundwater withdrawal in the late 1980s. The average subsidence rate during 1996-2005 was four times of the rate during 1972-1988. Figure 1 shows the percentage of the deformation of each aquifer and all of the aquitards to the total land subsidence during 1980-2000. The increasing percentage of subsidence caused by deformation of aquifers during 1996-2000 is attributed mostly to deformation occurring in AqIV. Fig. 2 shows the variations of deformation and groundwater level of AqIV in Yangpu District, which is located in the urban center of Shanghai. As shown in Fig. 2, deformation of AqIV lags the recovery of groundwater level.

\section{Mechanism of land subsidence}

\subsection{Urbanization-induced land subsidence}

Much infrastructures has been constructed in Shanghai since the 1990s. Studies of recent accelerated subsidence associated with urbanization point to two main causes: (i) the additional stresses caused by the building loads; (ii) the reduction

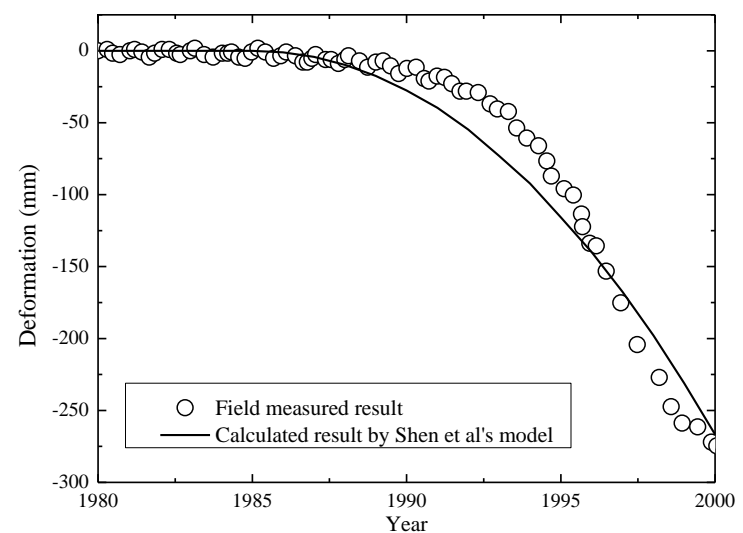

Figure 3. Comparison of simulated deformation using Cosserat mechanics to measured deformation of AqIV at Laodong Park (modified from Shen et al., 2013).

of recharged groundwater volume due to the cut-off effect imposed by underground structures penetrating the shallow portion of the aquifer system on groundwater flow. The cutoff effect influences only the deformation of the upper strata overlying AqII. It cannot explain the continuous deformation mechanism of the deeper aquifers (e.g. AqIV).

\subsection{Deformation of the sand}

The compaction of the aquitards due to the drawdown of the groundwater level has been considered the main factor causing land subsidence. However, situ data collected over the past twenty years indicate that deformation of the aquifers cannot be ignored and has become significant.

It was proposed to be the impact of the silt particles in the sand strata. Wang et al. (2010) concluded sand creep to be mainly responsible for the land subsidence. But the sand creep in aquifer could not create such scale of aquifer compaction. Thus, the sand creep theory can be used to illustrate the new phenomenon of the land subsidence to a degree. Some researchers proposed that deformation creep of sand just partly explained the magnitude and timing of the subsidence, that the deformation and subsidence lagged the recovery of the groundwater level (Zhang et al., 2007). 


\subsection{Research based on Cosserat mechanics}

Cai (2004) proposed that sand in aquifers would yield when the shear force was high enough. Groundwater pumping from the aquifer results in a large hydraulic gradient in the aquifer. This hydraulic gradient will cause an unbalanced shear stress in the aquifer. Cosserat continuum mechanics was proposed to describe the deformation of a continuous medium under shear stress, which is different from Cauchy mechanics (Budhu and Adiyaman, 2010). Shen et al. (2013) analysed the land subsidence in Shanghai based on Cosserat mechanics, as shown in Fig. 3. The result indicated the model based on Cosserat mechanics simulated the measured data well.

\subsection{Internal erosion of fine particles in sand}

An alternative mechanism causing subsidence in Shanghai is proposed here. Large quantities of silt and clay particles dispersed within the matrix pores of the aquifers in Shanghai (Wei et al., 2010a, b). The impact of these particles on the deformation of the aquifers is very small when the particles are static (Zhang et al., 2007). The hydraulic gradients induced by groundwater pumping can lead to shear stress in the aquifers and seepage stress in the silt and clay particles. The hydraulic gradients would lead to movement of the silt and clay particles in the pores of the aquifer, namely internal erosion of the particles. The internal erosion would result in the redistribution of land subsidence in both space and time. So it is important to investigate the mechanism of the internal erosion of the fine-grained particles and its impact on land subsidence in Shanghai.

\section{Conclusions}

Recently land subsidence in Shanghai is attributed to deformation occurring in the aquifers (eapecially Aq04) that continues and lags drawdowns. The traditional theory of aquifersystem compaction embodied in the aquitard drainage model cannot reasonably explain these phenomena. Research to investigate potential alternative mechanisms is addressing cutoff of groundwater flow caused by urban construction, sand creep, shear stress on soils induced by hydraulic gradients, and internal erosion of the fine-grained particles dispersed in the aquifers.

Acknowledgements. The research work described herein was funded by the National Nature Science Foundation of China (Grant No. 41472252) and partially funded by the National Basic Research Program of China (973 Program: 2015CB057806). These financial supports are gratefully acknowledged.

\section{References}

Budhu, M. and Adiyaman, I. B.: Mechanics of land subsidence due to groundwater pumping, Int. J. Numer. Anal. Met., 34, 14591478, 2010.

Cai, Z. Y.: The deformation behavior of sand, Yellow River Conservancy Press, China, 172 pp. 2004.

Shen, S. L., Ma, L., Xu, Y. S., and Yin, Z. Y.: Interpretation of increased deformation rate in aquifer IV due to groundwater pumping in Shanghai, Can. Geotech. J., 50, 1129-1142, 2013.

Wang, F., Miao, L. C., and Lv, W. H.: Study on the new deformation characteristics of the pumped aquifers in $\mathrm{Su}-\mathrm{Xi}$-Chang area, China, Geoenvironmental Engineering and Geotechnics (GSP 204), edited by: He, Q. and Shen, S. L., ASCE Press, Reston, Virginia, 57-62, 2010.

Wei, Z. X., Zhai, G. Y., and Yan, X. X.: Shanghai Urban Geology, Geology Press, Beijing, China, 123 pp., 2010a.

Wei, Z. X., Zhai, G. Y., and Yan, X. X.: Shanghai Urban Geology, Geology Press, Beijing, China, 374 pp., 2010b.

Xu, Y. S., Shen, S. L., and Du, Y. J.: Geological and hydrogeological environment in Shanghai with geohazards to construction and maintenance of infrastructures, Eng. Geol., 109, 241-254, 2009.

Zhang, Y., Xue, Y. Q., Wu, J. C., and Ye, S. J.: Stress-strain measurements of deforming aquifer systems that underlie Shanghai, China, Environmental and Engineering Geoscience, 13, 217228, 2007. 